\title{
Using exosomal miRNAs extracted from porcine follicular fluid to investigate their role in oocyte development
}

\author{
Junhe Hu* (D), Jinyi Dong, Zhi Zeng, Juan Wu, Xiansheng Tan, Tao Tang, Jiao Yan and Chenzhong Jin
}

\begin{abstract}
s
Background: Follicular development is crucial to normal oocyte maturation, with follicular size closely related to oocyte maturation. To better understand the molecular mechanisms behind porcine oocyte maturation, we obtained exosomal miRNA from porcine follicular fluid (PFF). These miRNA samples were then sequenced and analyzed regarding their different follicular sizes, as described in the methods section.
\end{abstract}

Results: First, these results showed that this process successfully isolated PFF exosomes. Nearly all valid reads from the PFF exosomal sequencing data were successfully mapped to the porcine genome database. Second, we used hierarchical clustering methods to determine that significantly expressed miRNAs were clustered into A, B, C, and D groups in our heatmap according to different follicle sizes. These results allowed for the targeting of potential mRNAs genes related to porcine oocyte development. Third, we chose ten, significantly expressed miRNAs and predicted their target genes for further GO analysis. These results showed that the expression levels of neurotransmitter secretion genes were greatly changed, as were many target genes involved in the regulation of FSH secretion. Notably, these are genes that are very closely related to oocyte maturation in growing follicles. We then used pathway analysis for these targeted genes based on the originally selected ten miRNAs. Results indicated that the pathways were mainly related to the biosynthesis of TGF-beta and its signaling pathway, which are very closely related to reproductive system functions.

Conclusions: Finally, these exosomal miRNAs obtained from PFF may provide a valuable addition to our understanding of the mechanism of porcine oocyte maturation. It is also likely that these exosomal miRNAs could function as molecular biomarkers to choose high-quality oocytes and allow for in vitro porcine embryo production.

Keywords: Exosomes, Porcine follicular fluid (PFF), Oocyte maturation, Follicular development, miRNA

\section{Background}

It is well known that oocyte maturation is strongly related to follicular growth and development [1]. As the follicles grow, their size is closely accompanied by increased oocyte diameter, indicating the ever-progressing maturation status of the oocyte. Many past studies have shown that oocyte quality is highly correlated with

\footnotetext{
*Correspondence: 260477247@qq.com; junhe_hu@126.com College of Agriculture and Biotechnology, Hunan University of Humanities, Science and Technology, Road Dingxing 7\#, Loudi City 417000, HuNan Province, China
}

oocyte diameter and later embryo development [1-4]. Moreover, some bovine oocyte maturation increases the volume of follicular fluid, owing to the larger follicle size. This may improve overall oocyte nuclear and cytoplasmic maturation when compared to follicles with smaller sizes and lower fluid volumes [5]. Given this, follicular size is a good predictor of oocyte quality and potential development and is a useful tool to better understand the molecular mechanisms of oocyte maturation.

Exosomes (EXs) are small $(30-150 \mathrm{~nm})$, cell-derived vesicles that are present in many-and perhaps all-

\section{$\mathrm{BMC}$}

(c) The Author(s). 2020 Open Access This article is licensed under a Creative Commons Attribution 4.0 International License, which permits use, sharing, adaptation, distribution and reproduction in any medium or format, as long as you give appropriate credit to the original author(s) and the source, provide a link to the Creative Commons licence, and indicate if changes were made. The images or other third party material in this article are included in the article's Creative Commons licence, unless indicated otherwise in a credit line to the material. If material is not included in the article's Creative Commons licence and your intended use is not permitted by statutory regulation or exceeds the permitted use, you will need to obtain permission directly from the copyright holder. To view a copy of this licence, visit http://creativecommons.org/licenses/by/4.0/ The Creative Commons Public Domain Dedication waiver (http://creativecommons.org/publicdomain/zero/1.0/) applies to the data made available in this article, unless otherwise stated in a credit line to the data. 
eukaryotic fluids, including human follicular fluid, blood, and cultured cellular medium. Moreover, past work has found that EXs contain a large number of biologically active molecular substances, such as proteins, mRNAs, and miRNAs. These substances exert myriad biological functions and are released from the cells and into the extracellular environment through budding and fission from the plasma membrane [6].

Structurally, EXs are formed by the invagination of multivesicular bodies in the lumen, which then fuse to the plasma membrane and release their contents to the cells in a manner that extracellularly transports the carrie [7]. In the cell and under normal physiological conditions, EXs are separated from the vesicular structure in the endoplasmic reticulum. Transport to the plasma membrane allows extracellular release and for EXs to exert regulatory control over normal physiological functions [8]. Given this, EXs likely play an important role in regulating oocyte physiological functions by transporting materials. In turn, these have targeted, cell signaling functions by containing a variety of RNAs [9].

Past work has reported that EXs exist under normal physiological conditions in horse [10] as well as human [11] follicular fluid. EXs also exist in bovine follicular fluid under conditions of reduced milk production [12]. Additional work has shown that these extracellular miRNAs play a role in regulating external environmental influences through the protective devices packaged as EXs [13]. Collectively, these molecules play essential roles across a wide range of physiological processes, some of which play a critical role in reproduction functions (e.g., follicular development and oocyte maturation) [14]. More specifically, past work has shown that miRNAs exist in porcine follicular fluids [12]; however, there is only a few limited reports about non-coding exosomal RNA transcripts in PFF to affect oocyte development.

Given this past work and our current understanding, it is very likely that EXs play a vital role in the relationship and regulation of associated cells in the follicular fluid during oocyte growth and development, which is achieved by their packaged biological materials, including miRNAs. Although our knowledge regarding oocyte quality and development has significantly improved in recent years, the molecular mechanisms that determine and regulate oocyte development remain unclear. Given this, we sought to conduct a study to compare the expression of exosomal, non-coding RNA transcripts from the PFF of different-sized follicles.

The results of this study substantially revise our understanding of the content of porcine follicular fluid exosomes and how they influence oocyte maturation by interactions with follicular somatic cells and cumulus cells around the oocytes. Ultimately, this work lays the foundation for future investigations regarding the role and mechanistic importance of PFF exosomal miRNAs in oocyte development. Therefore, the objective of this study was to identify and analyze the transcriptomic profiles of PFF exosomes derived from different-sized follicles using RNA high-throughput sequencing technology.

\section{Methods}

\section{Porcine follicular fluid samples collection}

All experimental porcine ovaries were collected from a local abattoir (usually 60 porcine ovaries each time collected from QinYangMuYe Limited Responsibility Company, LouDi city, HuNan Province, China) and transported to our lab within $2 \mathrm{~h}$ of slaughter in a thermo-flask containing penicillin and streptomycin. All experiments were conducted in accordance with the Institutional Ethics Committee of Hunan University of Humanities, Science and Technology. Ovaries were washed at least three times with physiological saline solution and porcine follicular fluid was collected by separately aspirating with a 23-gauge needle attached to a 5 $\mathrm{mL}$ syringe from small follicles (small follicles only; $<3$ $\mathrm{mm}$ [group A as control group] and 3-5 mm [group B]) or a 20 -gauge needle attached to a $10 \mathrm{~mL}$ syringe from large follicles (large follicles only; $5-8 \mathrm{~mm}$ [group C] and $>8 \mathrm{~mm}$ [group D], which each group has three duplicate samples shown as following: A3, A5 and A6 in group A; B3, B5 and B6 in group B; C3, C4 and C5 in group C; D1, D5, and D6 in group D. Follicle diameter was measured as previously reported [15]. All follicular fluid samples were centrifuged at $1300 \times \mathrm{g}$ for $15 \mathrm{~min}$ to remove any cells; at least $10 \mathrm{~mL}$ suspended follicular fluid was stored at $-80{ }^{\circ} \mathrm{C}$ until later experiments, and precipitated blood and the other material was $\mathrm{s}$ discarded.

\section{Exosome purification and characterization}

Porcine Follicular Fluid exosomes were purified and characterized according to previously published protocols with slight modifications [16]. Briefly, the isolation method used was as follows: Pooled 12 samples (total volume $15 \mathrm{~mL}$ ) was centrifuged at $1300 \times \mathrm{g}$ for $15 \mathrm{~min}$ at $4{ }^{\circ} \mathrm{C}$ to separate and isolate any debris. The supernatant was then transferred to a separate $15 \mathrm{~mL}$ ultracentrifuge tubes, after which it was ultracentrifuged at $16,500 \times \mathrm{g}$ for $30 \mathrm{~min}$ at $4{ }^{\circ} \mathrm{C}$. The resulting supernatant was then filtered through a $0.2 \mathrm{~mm}$ syringe filter to obtain the exosome-containing medium. Finally, exosomes were pelleted after ultracentrifugation at $120,000 \times \mathrm{g}$ for $70 \mathrm{~min}$ at $4{ }^{\circ} \mathrm{C}$ and stored at $-80^{\circ} \mathrm{C}$ until later analysis.

Exosome (EX) pellets were suspended in PBS for electron microscopy (EM) analysis. First, resuspended EXs samples $(5-10 \mu \mathrm{L}$ per sample) were added to the copper mesh and precipitated for $3 \mathrm{~min}$. Filter paper was used to absorb any volatile liquid from the edge. After rinsing 
with PBS, negative dying of phosphotungstic acid was performed. The sample was then dried at room temperature $(2 \mathrm{~min})$ for subsequent imaging (EM operating voltage $80-120 \mathrm{kv}$ ).

\section{Construction of exosomal small RNA library}

Exosome pellets were firstly resuspended in Trizol (Thermo Fisher Technology (China) Co., Ltd., Shanghai, China) for further RNA isolation. A small EX RNA library was then constructed using total RNA from $15 \mathrm{~mL}$ pooled follicular fluid. Small RNA cloning, sequencing, and analysis were conducted as previously described using QIAseq ${ }^{\circ}$ miRNA Library Kit [17]. Briefly, 20 ng of total RNA underwent rRNA depletion and DNase digestion using a NEBNext rRNA Depletion Kit (New England Biolabs (Beijing) LTD, Beijing, China) according to the manufacturer's protocol. A nucleoMag NGS Cleanup and Size Select Kit (Thermo Fisher Technology (China) Co.,Ltd., Shanghai, China,) was used for sample purification and library size selection. RNA samples were purified, fragmented at $94{ }^{\circ} \mathrm{C}$ for $15 \mathrm{~min}$, and primed with random primers. Samples were then converted to double-stranded cDNA, purified, and adapters were ligated to the $3^{\prime}$ and $5^{\prime}$ ends. The cDNA samples were amplified by PCR (14 cycles) using indexing forward primers and a universal reverse primer. After PCR amplification, RNA libraries were purified and quality control of RNA was conducted using an Agilent 2100 Bioanalyzer (Agilent Technologies (China) Co., Ltd., Beijing, China).

\section{RNA-Seq data analysis of EXs obtained from porcine follicular fluids}

Sequencing adaptors and low-complexity reads were removed in an initial data filtering step. The quality of the reads was then checked using the FASTQC program freely from the internet. Reads were then aligned against a swine reference genome (Sscrofa11.1, January 2017), which was downloaded from the Swine Genome Sequencing Consortium project (http://www.ensembl.org/) and used for all subsequent bioinformatic analyses. Finally, we applied a DEBseq-counts algorithm to filter the differentially expressed genes after significant analysis and FDR analysis under the following criteria: Log2FC > 1 or FDR $<0.05$. This was done to select for any significantly expressed genes for additional research. Functional annotation was performed using the Database for Annotation, Visualization and Integrated Discovery (DAVID) v6.8 (http://david.ncifcrf.gov). Pathway analysis was conducted using the download annotation data from KEGG (http://www.genome.jp/kegg/) and Cytoscape (https://cytoscape.org/) software.

\section{GO and pathway analyses}

Based on the hierarchical structure of GO, the mutual control and subordinate relationships between all GO were organized into a database. By constructing a functional relationship network, it is easy to summarize the functional groups affected by the experiment and the intrinsic subordinate relationships of the significant functions. Functional regulation analysis was performed using the significant GO-Term $(p<0.01)$ in GOAnalysis by differential genes to construct a functional regulatory network. GO classification can describe the function of genes from various aspects, and can be divided into three main groups: Biological Process (BP), Molecular Function (MF), and Cellular Component. The selected differentially expressed genes were annotated using this pathway approach and based on the KEGG database; all pathway terms in which the differentially expressed genes and their target genes were then obtained.

\section{Statistical analysis}

Both the back-spliced junction reads and the linear mapped reads were combined and scaled to reads per kilobase per million mapped reads (RPKM) to quantify miRNA expression levels. Differences in these miRNA expression profiles between groups A, B, C, and D were analyzed using Student's t-test. $P<0.05$ was considered statistically significant.

\section{Results}

Exosome isolation and quality control of the RNAsequence data

Porcine Follicular Fluid exosomes were successfully separated and further verified according to the above methods. These exosomes were also analyzed using transmission electron microscopy (JEM-1200EX) with an operating voltage of 80-120 kv (Fig. 1a-b). Exosome pellets were resuspended in phosphate-buffered saline (PBS) for subsequent electron microscopy analysis to further verify their characterization according to previously published results [18]. FastQC software (https://www.bioinformatics.babraham.ac.uk/projects/fastqc/) was used to perform a full evaluation of the sequenced data, including length distribution, quality score, and GC content. The quality control of the raw sequencing data sought to provide a quick impression of whether the data had any problems. This step was necessary to ensure awareness of any problems prior to further analysis according to a previously published method [19].

miRNAs with significant expression and their heatmap analysis

RNA sequencing and analysis were conducted using 16 samples: Group A: A3, A5, and A6; Group B: B3, B5, 

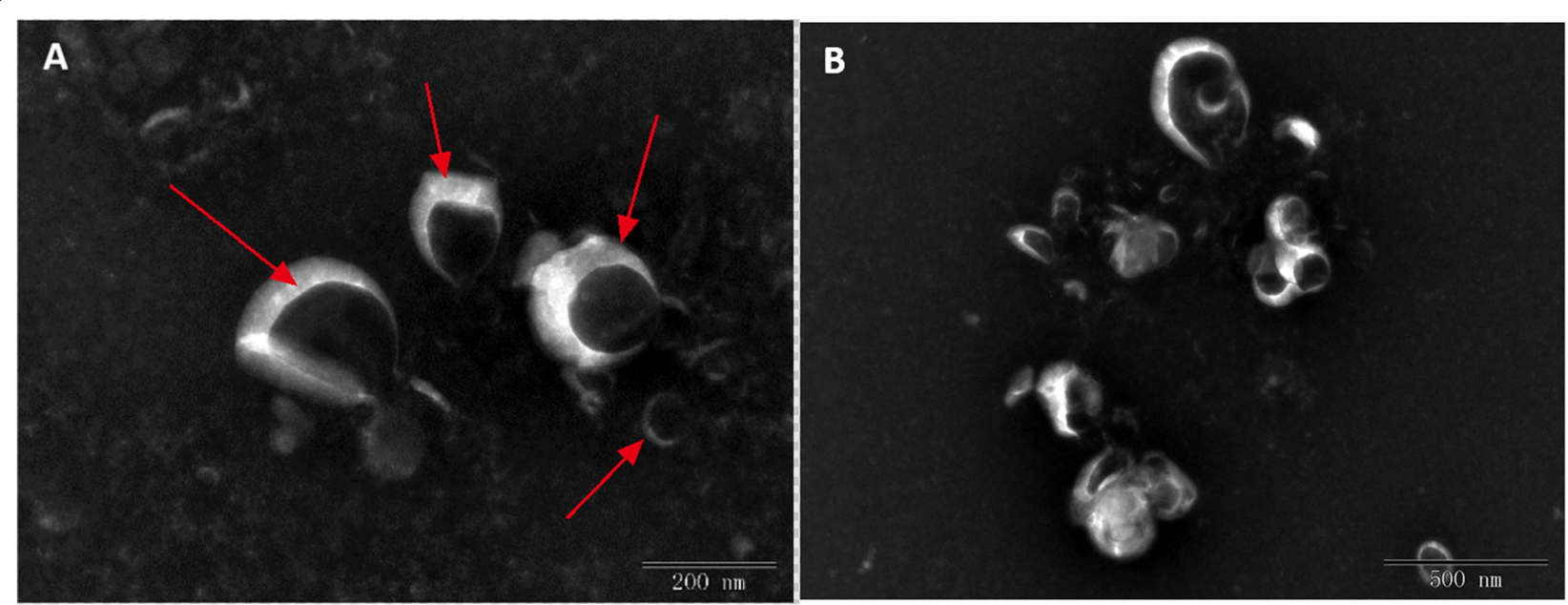

Fig. 1 PFF exosome confirmation using transmission electron microscopy (TEM). a. TEM of exosomes imaged using 200 nm microscope rulers. Exosomes present a cup-shaped morphology (indicated as red arrow). b. TEM of exosomes imaged using $500 \mathrm{~nm}$ size microscope rulers

and B6; Group C: C3, C4, and C5; Group D: D1, D5, and D6. Three replicates for each sample were used per group. Samples were prepared by collecting different size follicles according to the above methods. On average, the total number of valid reads obtained from PFF exosomes was approximately 6.50 million for group A, 4.30 million for group B, 6.90 million for group C, and 9.30 million for group D (Table 1). Overall, approximately $99 \%$ of all valid reads were from groups A-D. From these and as indicated in Table 1, all 12 samples were successfully mapped to the porcine non-coding RNA database for further research.

These differentially expressed miRNAs were further analyzed using hierarchical clustering methods to form the heatmap comparing groups B to A (small size follicles: control group; Fig. 2a). As shown in Fig. 2b, we chose significant, differentially expressed miRNAs from group A-miR-10a-5p, miR-200b, miR-429, miR-192,

Table 1 The sequencing data obtained after sequencing of different experimental groups were compared with the existing swine genome statistics

\begin{tabular}{|c|c|c|c|c|c|c|c|c|c|c|c|c|}
\hline \multirow[t]{2}{*}{ Statistics } & $\mathrm{A} 1$ & $\mathrm{~A} 2$ & A3 & B1 & B2 & B3 & $\mathrm{C} 1$ & $\mathrm{C} 2$ & C3 & D1 & D2 & D3 \\
\hline & $\begin{array}{l}\text { A3 } \\
\text { Result }\end{array}$ & $\begin{array}{l}\text { A5 } \\
\text { Result }\end{array}$ & $\begin{array}{l}\text { A6 } \\
\text { Result }\end{array}$ & $\begin{array}{l}\text { B3 } \\
\text { Result }\end{array}$ & $\begin{array}{l}\text { B5 } \\
\text { Result }\end{array}$ & $\begin{array}{l}\text { B6 } \\
\text { Result }\end{array}$ & $\begin{array}{l}\text { C3 } \\
\text { Result }\end{array}$ & $\begin{array}{l}\text { C4 } \\
\text { Result }\end{array}$ & $\begin{array}{l}\text { C5 } \\
\text { Result }\end{array}$ & $\begin{array}{l}\text { D1 } \\
\text { Result }\end{array}$ & $\begin{array}{l}\text { D5 } \\
\text { Result }\end{array}$ & $\begin{array}{l}\text { D6 } \\
\text { Result }\end{array}$ \\
\hline All & $\begin{array}{l}9.74 \mathrm{E}+ \\
06\end{array}$ & $\begin{array}{l}8.28 \mathrm{E}+ \\
06\end{array}$ & $\begin{array}{l}\text { 1.10E+ } \\
07\end{array}$ & $\begin{array}{l}5.51 \mathrm{E}+ \\
06\end{array}$ & $\begin{array}{l}7.98 \mathrm{E}+ \\
06\end{array}$ & $\begin{array}{l}7.30 \mathrm{E}+ \\
06\end{array}$ & $\begin{array}{l}6.31 \mathrm{E}+ \\
06\end{array}$ & $\begin{array}{l}5.84 \mathrm{E}+ \\
06\end{array}$ & $\begin{array}{l}8.49 E+ \\
06\end{array}$ & $\begin{array}{l}1.01 \mathrm{E}+ \\
07\end{array}$ & $\begin{array}{l}\text { 7.97E+ } \\
06\end{array}$ & $\begin{array}{l}1.00 \mathrm{E}+ \\
07\end{array}$ \\
\hline UnMapped & 24,908 & 14,627 & 21,357 & 18,332 & 29,536 & 18,978 & 23,296 & 15,669 & 31,405 & 33,521 & 22,323 & 90,820 \\
\hline Mapped & $\begin{array}{l}9.72 \mathrm{E}+ \\
06\end{array}$ & $\begin{array}{l}8.26 \mathrm{E}+ \\
06\end{array}$ & $\begin{array}{l}\text { 1.10E+ } \\
07\end{array}$ & $\begin{array}{l}5.49 \mathrm{E}+ \\
06\end{array}$ & $\begin{array}{l}7.95 E+ \\
06\end{array}$ & $\begin{array}{l}7.29 E+ \\
06\end{array}$ & $\begin{array}{l}6.29 \mathrm{E}+ \\
06\end{array}$ & $\begin{array}{l}5.83 E+ \\
06\end{array}$ & $\begin{array}{l}8.46 \mathrm{E}+ \\
06\end{array}$ & $\begin{array}{l}1.01 \mathrm{E}+ \\
07\end{array}$ & $\begin{array}{l}7.95 E+ \\
06\end{array}$ & $\begin{array}{l}9.91 \mathrm{E}+ \\
06\end{array}$ \\
\hline MappedRate & 0.997 & 0.998 & 0.998 & 0.997 & 0.996 & 0.997 & 0.996 & 0.997 & 0.996 & 0.997 & 0.997 & 0.991 \\
\hline UniqueMapped & 420,828 & 250,095 & 393,684 & 390,443 & 310,342 & 397,850 & 380,636 & 381,043 & 364,489 & 325,603 & 293,976 & 475,844 \\
\hline UniqueMappedRate & 0.043 & 0.03 & 0.036 & 0.071 & 0.039 & 0.054 & 0.06 & 0.065 & 0.043 & 0.032 & 0.037 & 0.048 \\
\hline RepeatMapped & $\begin{array}{l}9.30 \mathrm{E}+ \\
06\end{array}$ & $\begin{array}{l}8.01 \mathrm{E}+ \\
06\end{array}$ & $\begin{array}{l}1.06 \mathrm{E}+ \\
07\end{array}$ & $\begin{array}{l}5.10 \mathrm{E}+ \\
06\end{array}$ & $\begin{array}{l}7.64 \mathrm{E}+ \\
06\end{array}$ & $\begin{array}{l}6.89 \mathrm{E}+ \\
06\end{array}$ & $\begin{array}{l}5.91 \mathrm{E}+ \\
06\end{array}$ & $\begin{array}{l}5.45 E+ \\
06\end{array}$ & $\begin{array}{l}8.09 E+ \\
06\end{array}$ & $\begin{array}{l}9.74 \mathrm{E}+ \\
06\end{array}$ & $\begin{array}{l}7.65 E+ \\
06\end{array}$ & $\begin{array}{l}9.43 E+ \\
06\end{array}$ \\
\hline AllBase & $\begin{array}{l}2.25 \mathrm{E}+ \\
08\end{array}$ & $\begin{array}{l}1.80 \mathrm{E}+ \\
08\end{array}$ & $\begin{array}{l}2.35 E+ \\
08\end{array}$ & $\begin{array}{l}1.22 \mathrm{E}+ \\
08\end{array}$ & $\begin{array}{l}1.77 \mathrm{E}+ \\
08\end{array}$ & $\begin{array}{l}1.54 \mathrm{E}+ \\
08\end{array}$ & $\begin{array}{l}1.42 \mathrm{E}+ \\
08\end{array}$ & $\begin{array}{l}1.24 \mathrm{E}+ \\
08\end{array}$ & $\begin{array}{l}1.95 E+ \\
08\end{array}$ & $\begin{array}{l}2.54 \mathrm{E}+ \\
08\end{array}$ & $\begin{array}{l}1.88 \mathrm{E}+ \\
08\end{array}$ & $\begin{array}{l}2.15 E+ \\
08\end{array}$ \\
\hline UnMappedBase & 712,918 & 416,373 & 602,089 & 516,508 & 811,214 & 535,743 & 657,339 & 437,772 & 894,895 & 959,599 & 632,346 & $\begin{array}{l}2,564 \\
625\end{array}$ \\
\hline MappedBase & $\begin{array}{l}2.24 \mathrm{E}+ \\
08\end{array}$ & $\begin{array}{l}1.80 \mathrm{E}+ \\
08\end{array}$ & $\begin{array}{l}2.34 \mathrm{E}+ \\
08\end{array}$ & $\begin{array}{l}1.22 \mathrm{E}+ \\
08\end{array}$ & $\begin{array}{l}1.76 \mathrm{E}+ \\
08\end{array}$ & $\begin{array}{l}1.53 \mathrm{E}+ \\
08\end{array}$ & $\begin{array}{l}1.41 \mathrm{E}+ \\
08\end{array}$ & $\begin{array}{l}1.23 E+ \\
08\end{array}$ & $\begin{array}{l}1.94 \mathrm{E}+ \\
08\end{array}$ & $\begin{array}{l}2.53 \mathrm{E}+ \\
08\end{array}$ & $\begin{array}{l}1.87 E+ \\
08\end{array}$ & $\begin{array}{l}2.13 E+ \\
08\end{array}$ \\
\hline UniqueMappedBase & $\begin{array}{l}8.82 \mathrm{E}+ \\
06\end{array}$ & $\begin{array}{l}4.93 E+ \\
06\end{array}$ & $\begin{array}{l}7.57 \mathrm{E}+ \\
06\end{array}$ & $\begin{array}{l}\text { 7.67E+ } \\
06\end{array}$ & $\begin{array}{l}6.15 \mathrm{E}+ \\
06\end{array}$ & $\begin{array}{l}7.53 \mathrm{E}+ \\
06\end{array}$ & $\begin{array}{l}7.41 \mathrm{E}+ \\
06\end{array}$ & $\begin{array}{l}7.13 \mathrm{E}+ \\
06\end{array}$ & $\begin{array}{l}7.05 E+ \\
06\end{array}$ & $\begin{array}{l}6.74 \mathrm{E}+ \\
06\end{array}$ & $\begin{array}{l}5.98 \mathrm{E}+ \\
06\end{array}$ & $\begin{array}{l}9.61 \mathrm{E}+ \\
06\end{array}$ \\
\hline RepeatMappedBase & $\begin{array}{l}2.16 \mathrm{E}+ \\
08\end{array}$ & $\begin{array}{l}1.75 \mathrm{E}+ \\
08\end{array}$ & $\begin{array}{l}2.27 \mathrm{E}+ \\
08\end{array}$ & $\begin{array}{l}1.14 \mathrm{E}+ \\
08\end{array}$ & $\begin{array}{l}1.70 \mathrm{E}+ \\
08\end{array}$ & $\begin{array}{l}1.46 \mathrm{E}+ \\
08\end{array}$ & $\begin{array}{l}1.34 \mathrm{E}+ \\
08\end{array}$ & $\begin{array}{l}1.16 \mathrm{E}+ \\
08\end{array}$ & $\begin{array}{l}1.87 \mathrm{E}+ \\
08\end{array}$ & $\begin{array}{l}2.46 \mathrm{E}+ \\
08\end{array}$ & $\begin{array}{l}1.81 \mathrm{E}+ \\
08\end{array}$ & $\begin{array}{l}2.03 \mathrm{E}+ \\
08\end{array}$ \\
\hline
\end{tabular}



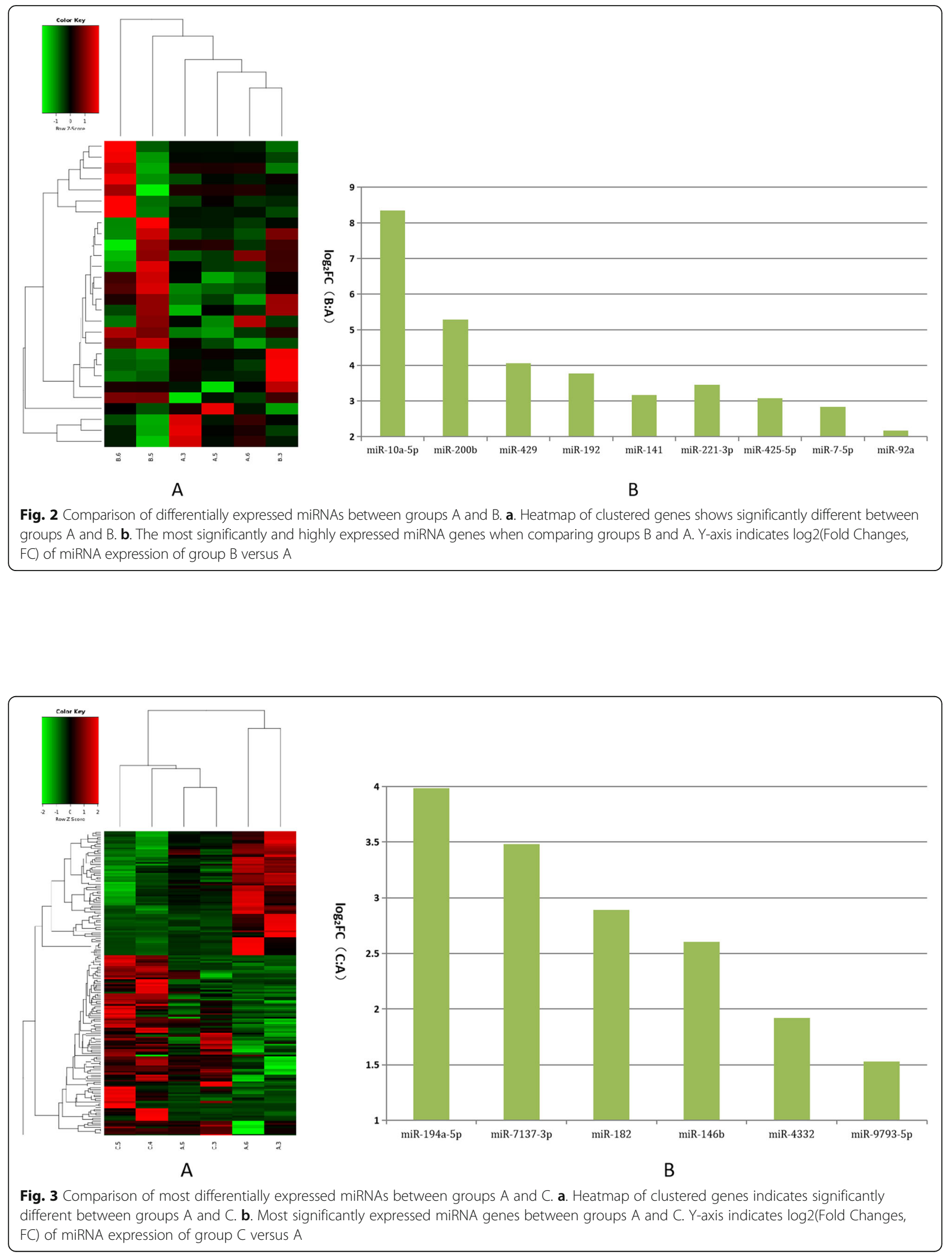
miR-141, miR-221-3p, miR-425-5p, miR-7-5p, and miR$92 \mathrm{a}$ - and compared these to the control. These differentially expressed miRNAs were further analyzed using hierarchical clustering methods to form the heatmap comparing groups $\mathrm{C}$ to A (control group; Fig. 3a). As shown in Fig. 3b, we chose significant, differentially expressed miRNAs from group A-miR-194a-5p, miR7137-3p, miR-182, miR-146b, miR-4332 and miR-9793$5 \mathrm{p}-$ and compared these to the control. Third, these differentially expressed miRNAs were further analyzed using hierarchical clustering methods to form the heatmap comparing groups D to A (control group; Fig. 4a). As shown in Fig. 4b, we chose significant, differentially expressed miRNAs from group A-miR-21-5p, miR26b-5p, miR-26a, miR-146a-5p, miR-202-5p, miR-29c, miR-24-3p, miR-199a-5p, and miR-10b-and compared these to the control.

We further analyzed these differentially expressed miRNAs using hierarchical clustering methods to form the heatmap comparing groups $\mathrm{B}$ to $\mathrm{C}$ (Fig. 5a). We chose significant, differentially expressed miRNAsmiRNA-10a-5p, miRNA-200b, miRNA-95, miRNA-141, miRNA-92a, miRNA-221-3p, miRNA-7-5p, miRNA-192, miRNA-20a-5p, and let-7d-5p-from group B and compared them to group $C$ (Fig. 5b). These differentially expressed miRNAs were further analyzed using hierarchical clustering methods to form the heatmap comparing groups B to D (Fig. 6a). We chose significant, differentially expressed miRNAs-miR-200b, miR-10a-5p, miR141, miR-221-3p, miR-20a-5p, and miR-92a-of group B and compared these to group D (Fig. 6b). Finally, we further analyzed these differentially expressed miRNAs using hierarchical clustering methods to form the heatmap between groups $\mathrm{C}$ compared to group D (Fig. 7a). We chose significant, differentially expressed miRNAsmiR-335, miR-497, miR-19b, miR-130a, miR-29a-3p, miR-676-3p, miR-128, miR-125b, miR-99a-5p, and miR202-5p-from group C and compared them to group D (Fig. 7b).

\section{GO and pathway analysis for miRNA target genes}

Based on the above research results, we selected ten miRNAs among these four tested groups-miR-125b, let-7d-5p, miR-200b, miR-26a, miR-92a, miR-221-3p, miR-21-5p, miR-141, miR-99a-5p, and miR-10a-5p-as being related to porcine oocyte maturation (Figs. 2, 3, 4, 5,6 and 7). These selected miRNAs were then used with Miranda and RNA software to predict the targeting regulation relationship between the whole species of miRNAs. This was done by taking the intersection results of the two prediction software programs as the final target gene prediction results.

Using this approach, miR-125b, let-7d-5p, and miR$200 \mathrm{~b}$ were among the top 10 most highly expressed miRNAs from the four tested groups. This is sound evidence that these miRNAs have potential roles in regulating porcine oocyte development [20]. The parameters of this analysis were set as follows: energy_miranda $<-20$, score_miranda $>150$, energy_RNAhybird $<-25$. Our results showed 67 significant, differentially targeted genes

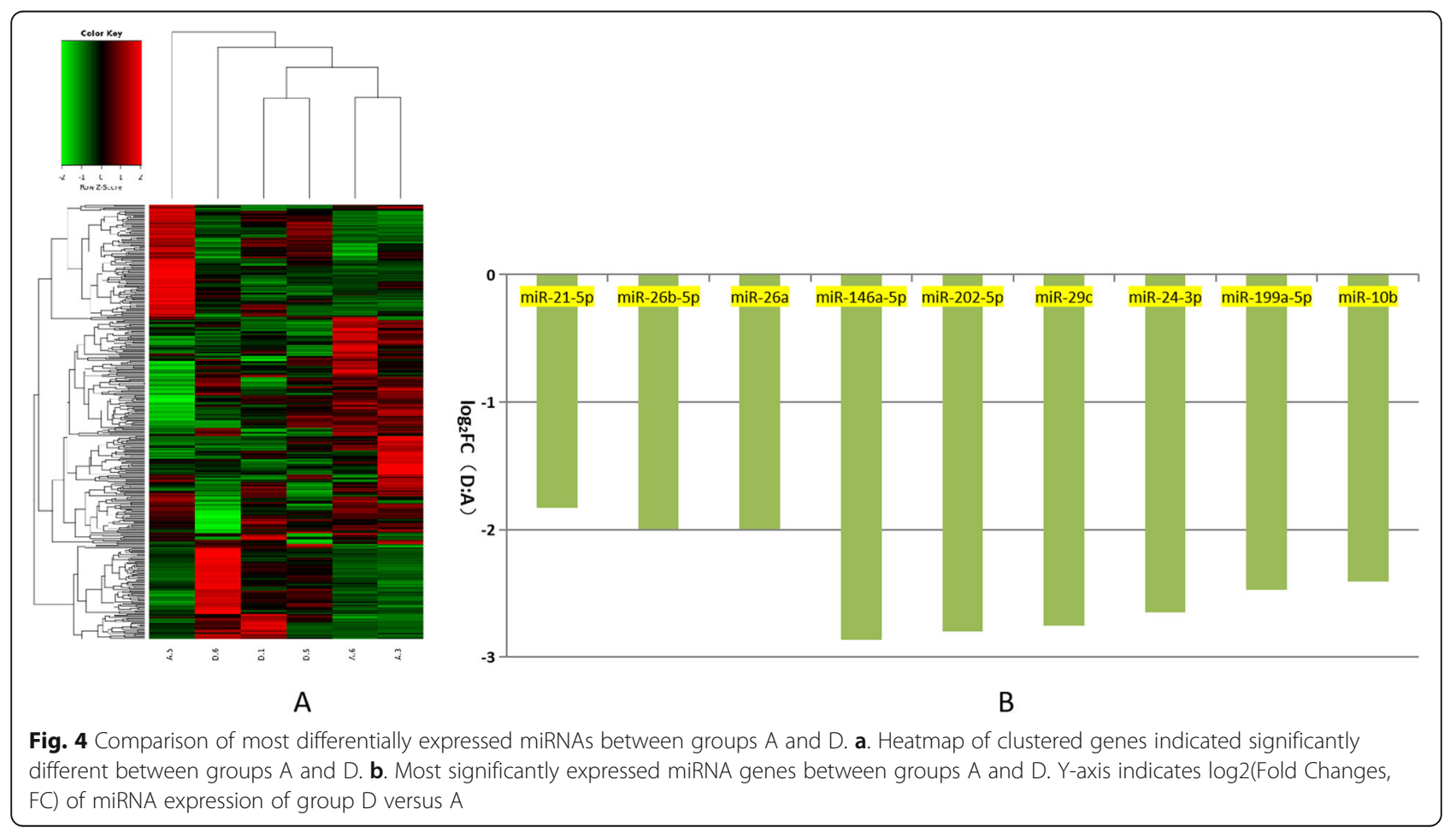



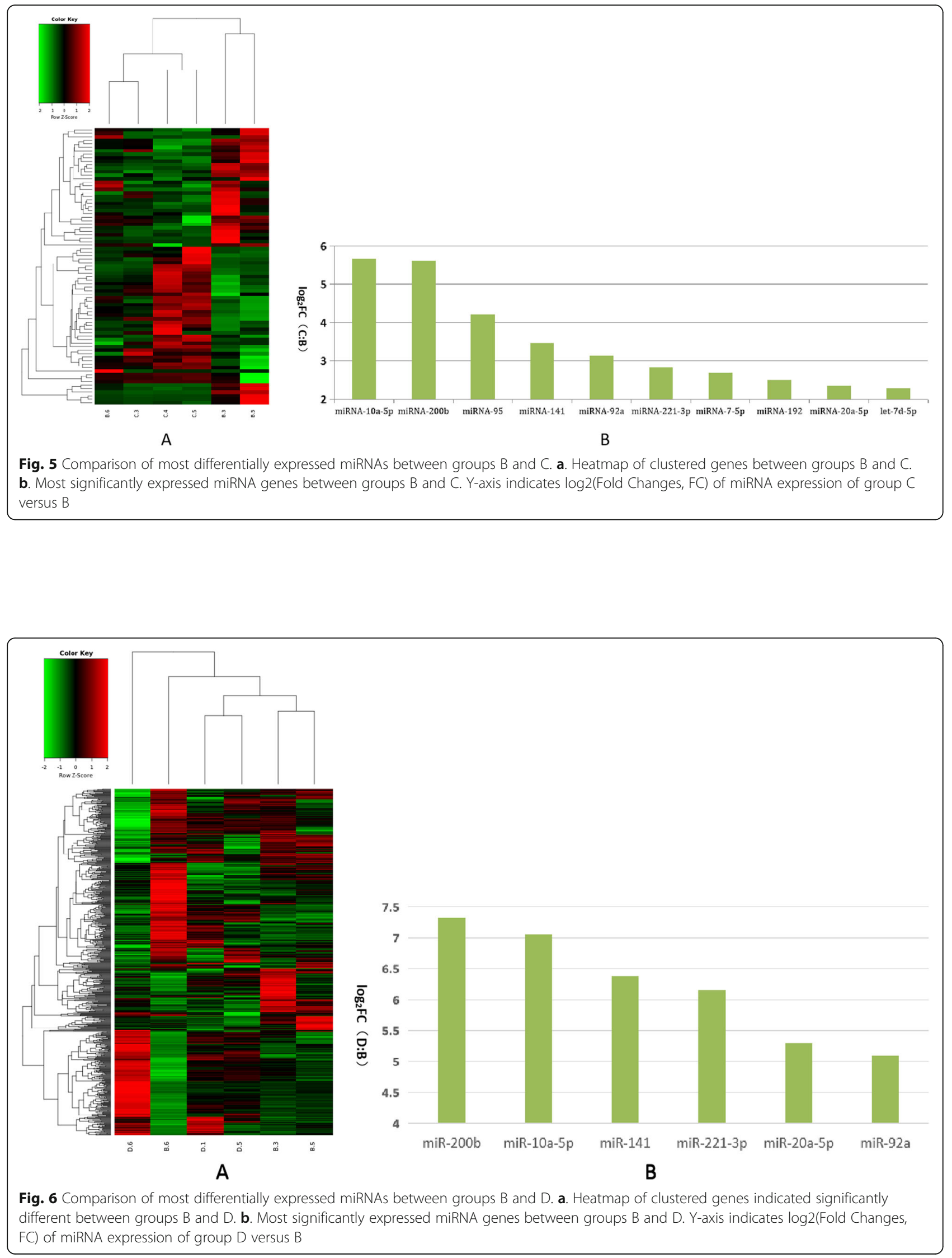


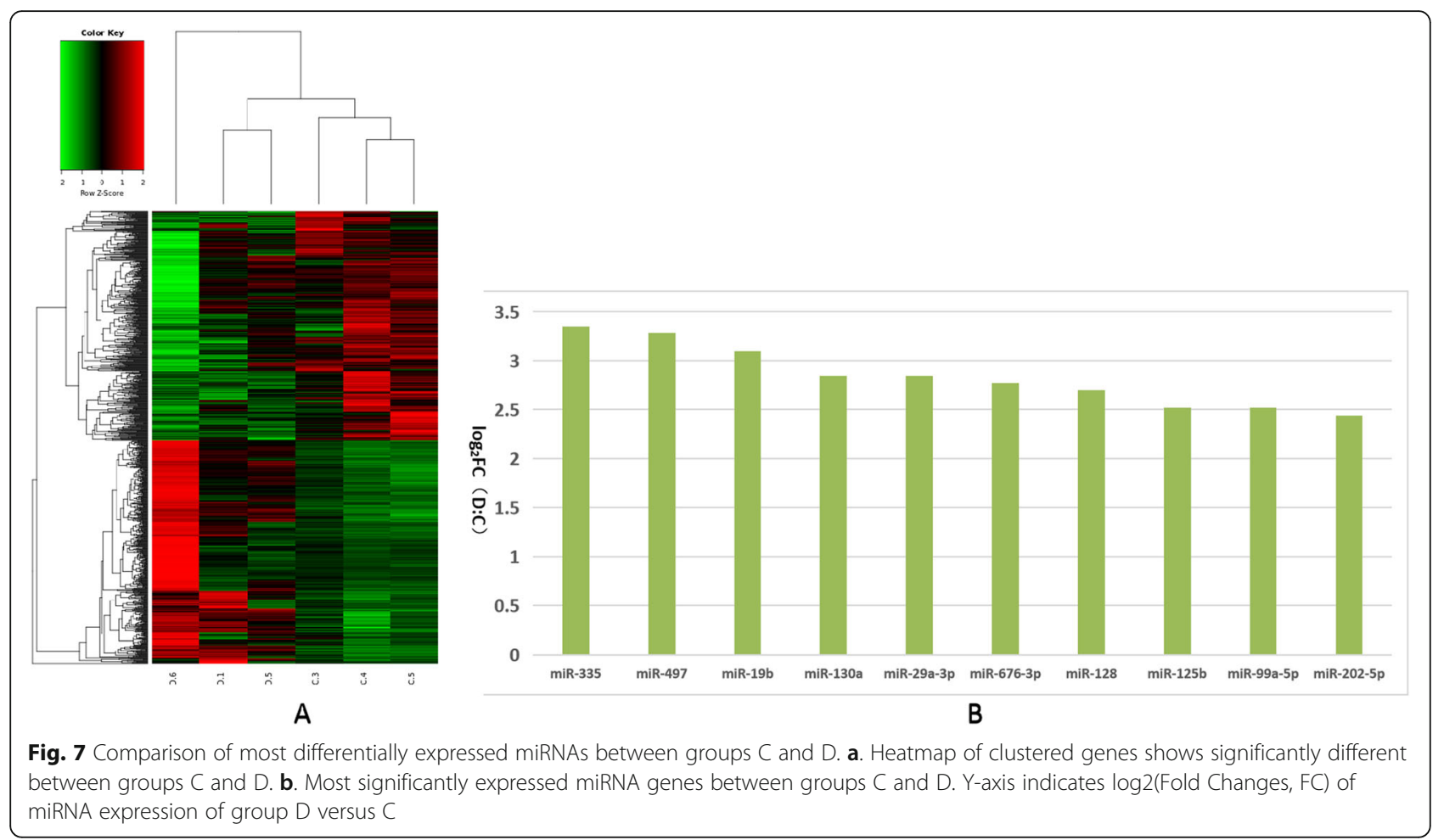

that were a hybrid between the Miranda and RNA software results. These results were then used to take GO further (Fig. 8) and to also take the pathway analysis further (Fig. 9).

These results showed that the gene number and significance to neurotransmitter secretion changed greatly across the GO enrichment scatter plot (Fig. 9). These results also show that the rich factor value of the regulation of follicle-stimulating hormone (FSH) secretion was almost 1 (Fig. 10). This indicated the functions of many targeting gene by these miRNAs were primarily focused on oocyte development by FSH simulating porcine follicular growth. As presented in the map in Fig. 11, we further clarified the interaction of these targeting mRNAs and miRNAs genes (miR-125b, let-7d-5p, miR200b, miR-26a, miR-92a and miR-221-3p). As indicated, these indicated genes were all closely related to reproductive system function.

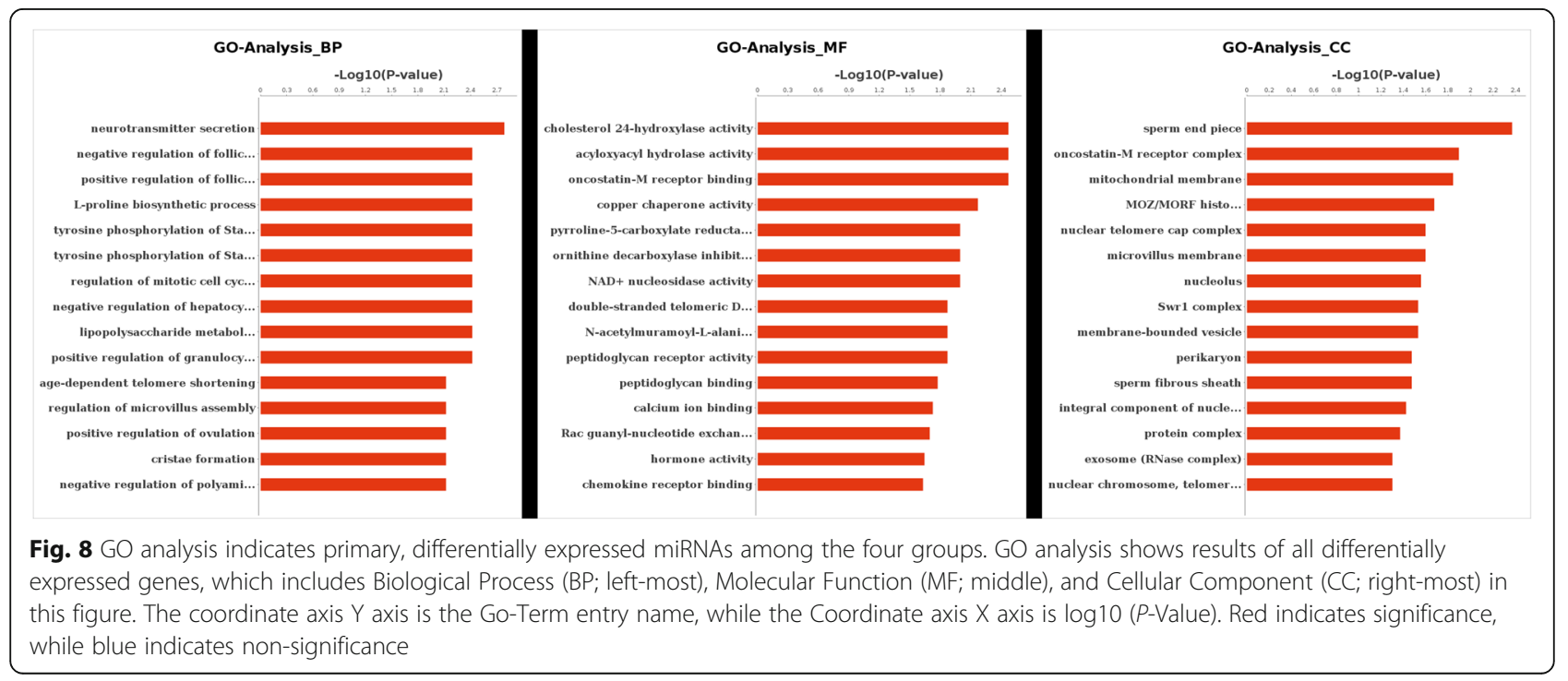




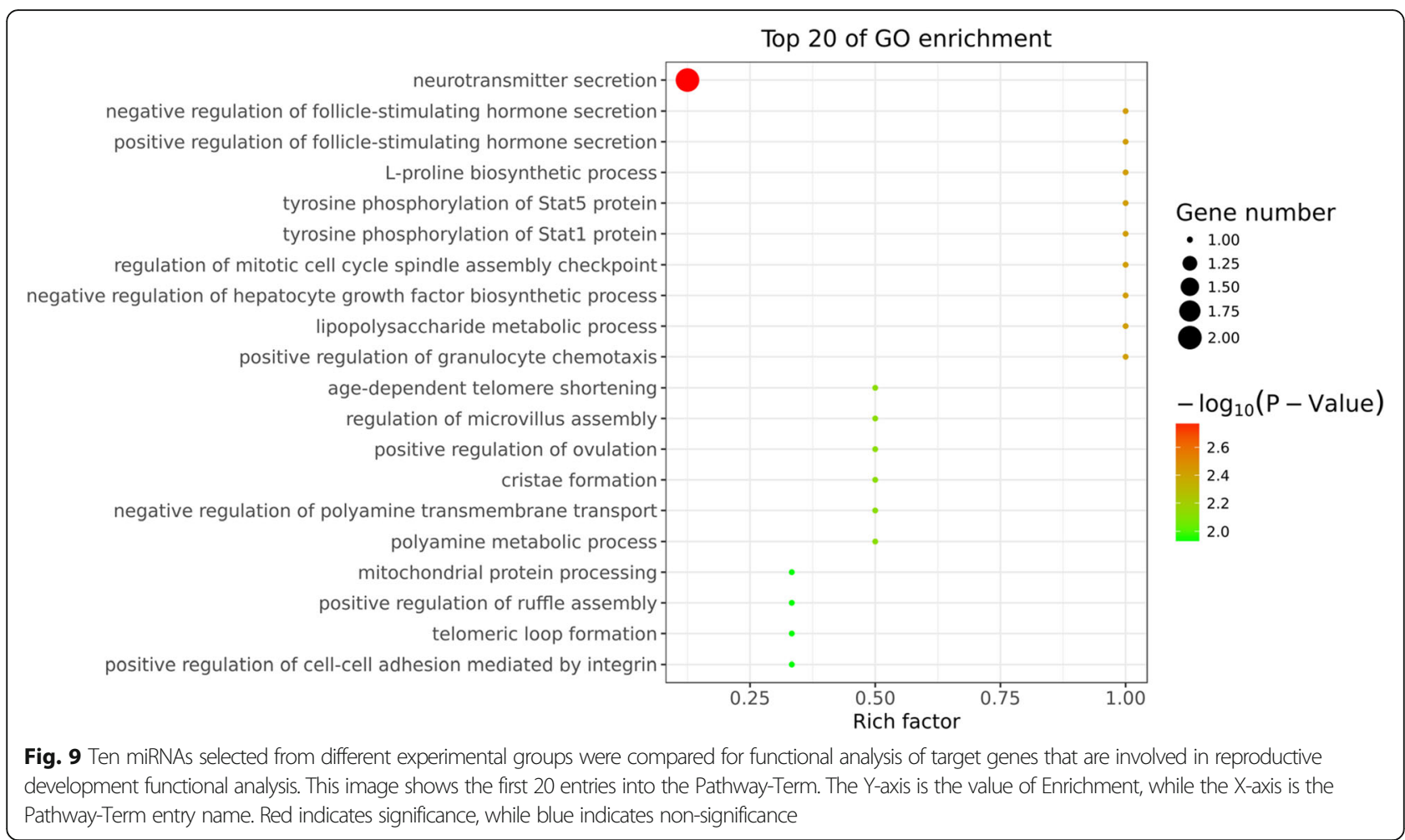

\section{Discussion}

As is already known, ovarian follicles provide a unique microenvironment for oocyte development and allow for interactions between follicular somatic cells and oocytes. Given this, it is crucial to study the components of follicular fluid to better elucidate their role in the mechanism of oocyte maturation. Previous work has shown that exosomes (EXs) are an essential carrier for the signal transduction occurring between follicular somatic cells and oocytes in follicular fluid [21, 22]. Here, PFF exosomes were successfully isolated and confirmed using transmission electron microscopy. Our findings were similar to those of other reports [23].

To better understand the molecular mechanism behind oocyte maturation, it is crucial to reveal the axis of follicular somatic cells-EXs-oocyte by studying the expressed genes in the PFF EXs at the level of the RNA. Past work has used bioinformatics analysis to identify potential miRNA targets which were very important to growth of porcine oocytes in follicles [24, 25]. In particular, follicle size has been shown to be closely related to oocyte development [26, 27].

Mature miRNAs are produced by a series of nucleasemediated cleavage processes of longer primary transcripts. These miRNAs are then assembled into RNAinduced silencing complexes to identify target genes, which is done by base complementary base pairing. The degree of complementarity guides the silencing complexes to their target genes, whereby they degrade or block the translation of their target genes. Given this, we conducted an miRNA sequencing experiment using a total of 12 PFF exosome samples (three repeats per group, with groups composed of different follicle sizes) according to previously described methods. First, our results showed that approximately $99 \%$ of all valid reads were with groups A-D. As indicated in Table 1, we successfully mapped 12 samples to the porcine non-coding RNA database for further analysis. Our results also showed that 8 miRNA genes obtained from PFF EXs (miR-10a-5p, miR-200b, miR-429, miR-192, miR-141, miR-221-3p, miR-425-5p, miR-7-5p and miR-92a) had significantly enhanced expression in porcine follicles with diameters $<3 \mathrm{~mm}$ to $5 \mathrm{~mm}$. Moreover, miR-10a-5p expression was almost 8 times higher than that in group A (Fig. 2). According to these results, it can be indicated that miR-10a-5p mainly limited expressed in small follicles (contained immature oocytes), but these miRNAs (miR-10a-5p, miR-200b, miR-429, miR-192, miR-141, miR-221-3p, miR-425-5p, miR-7-5p and miR-92a) enhanced the expression with follicle growth (from $5 \mathrm{~mm}$ diameter follicles to previous ovulation stage), which is very important to elucidate the mechanism of porcine oocyte maturation.

Our results also indicated that miR-10a family expression was closely related to reproductive system function. More specifically, miR-10a and miR-10b were both expressed at basal levels in granulosa cells, but were highly expressed in theca and stroma cells within the 


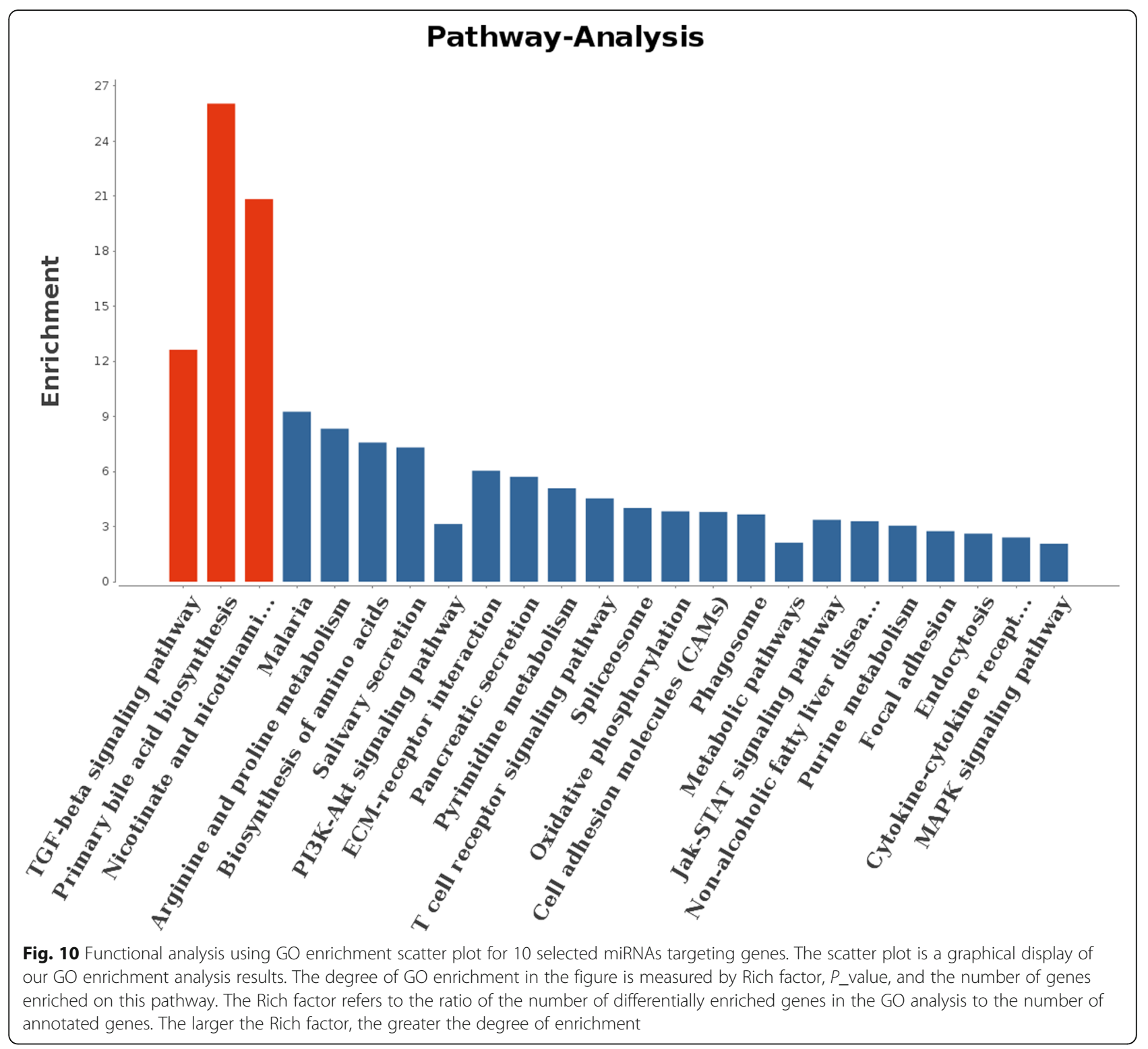

ovary. This indicated they could repress proliferation and induce apoptosis in human, mouse, and rat granulosa cells. This would partly occur by BDNF repression through direct binding to its 3' UTR, with the miR-10 family and the TGF- $\beta$ pathway forming a negative feedback loop in $\mathrm{GC}^{\mathrm{s}}$ [28]. With porcine follicles of larger diameter $(5-8 \mathrm{~mm})$, there was significantly enhanced expression of six miRNA genes obtained from PFF EXs (miR-194a-5p, miR-7137-3p,miR-182, miR-146b, miR4332 and miR-9793-5p) when compared to the control group $(<3 \mathrm{~mm})$. Of these, miR-194a-5p expression was almost four times higher than that of group A (Fig. 3). Exosomes act as carriers to follicles from the surrounding somatic cells as well as the body and blood to influence oocyte maturation. Moreover, immune stimulus has been shown to enhance vasodilatation to promote exosomal function $[29,30]$. Past work has also shown that miR-194a family expression plays an important role in immunological responses and function, including the flounder [31] and zebrafish [32] immune responses. Further results shown that miR-194a-5p is highly related to oocyte maturation of follicles growing stage, which can induce immune reaction to enhance ovary local blood circulation to provide more nutrients.

When follicles grow to a diameter of $8 \mathrm{~mm}, 9$ miRNA genes obtained from PFF EXs (miR-202-5p, miR-199a5p, miR-21-5p, miR-26b-5p, miR-26a, miR-29c, miR-24$3 p$, miR-146a-5p, and miR-10b) had significantly reduced expression when compared to the control group $(<3 \mathrm{~mm})$. Of these, both miR-46a-5p and miR-202a-5p gene expression levels were almost three times lower than those of group A (Fig. 4). It has been shown that 


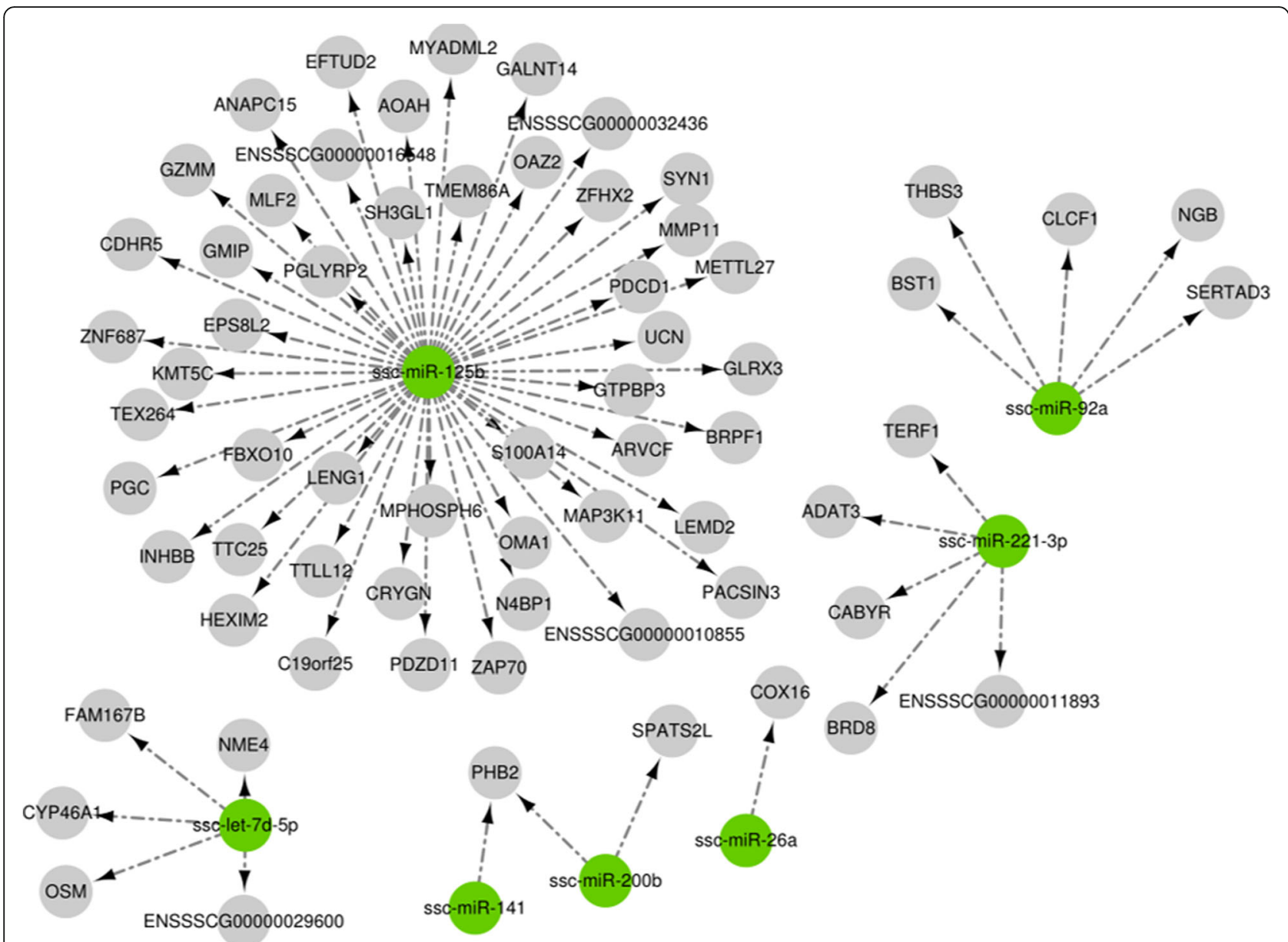

Fig. 11 Functional map of target gene interactions among 7 miRNAs selected from experimental groups. Seven different miRNA (green color) and their targeting mRNAs (gray color) are sorted by color

the miR-202a-5p gene is highly expressed in bovine unmaturated oocytes [33], while miR-199a-5p gene is highly expressed in germinal vesicle stage occytes [34]. From groups B, C, and D, these selected, differentially expressed miRNAs were all clustered in Figs. 5, 6, and 7 for further analysis. This analysis confirmed earlier work, indicating that some were closely related to oocyte development [35]. Based on the significant expression of the above miRNAs, we selected ten relevant miRNAsmiR-10a-5 ps, miR-200b, miR-141, miR-92a, miR-2213p, miR-21-5p, miR-26a, let-7d-5p, miR-125b and miR$99 a-5 p-$ related to porcine oocyte development for further target genes analysis. Currently, there is no gold standard for miRNA gene target analysis [36, 37]. Given this, we used Miranda and RNA software to predict the targeting regulation for further GO and pathway analyses according to previously reported papers [38, 39].

This analysis found selected miRNAs (miR-125b, let7d-5p, miR-200b, miR-26a, and miR-92a) were expressed in PFF exosomes obtained from different-sized follicles.
These miRNAs were also very closely related to oocyte development, which has been previously reported [40]. The gene number and their significance regarding neurotransmitter secretion changed greatly (Figs. 8 and 9). It is known that the activity of the hypothalamuspituitary-ovarian endocrine axis is very vigorous during processes related to porcine follicular growth [41]. These results also show that many targeted genes were involved in the regulation of FSH secretion (Figs. 7 and 8), This corroborates previous work, which has shown how FSH controls the follicular development in differentsized follicles $[42,43]$. Therefore, we concluded that the functions of many of these miRNA-targeted genes were primarily focused on oocyte development by FSH simulation. This effect occurs through the porcine follicular growth stage, from its early (group A), middle (group B), and matured (groups $C$ and D) stages. Collectively, these results showed that important pathways identified from this work included those related to the biosynthesis of TGF-beta signaling, primary bile acid biosynthesis, and 
both nicotinate and nicotinamides metabolism (Fig. 10). Importantly, these potential target genes are all closely related to oocyte development and follicle growth. Past work has also shown that many of these miRNAtargeted genes were mainly involved in TGF-beta-related signaling. This pathway may play a significant role during the early stages of porcine oocytes nuclear and cytoplasmic maturation.

It should be clarified that while these are potential genes predicted from our GO and pathway analyses, their associations as observed in previous published papers are limited. Some past work has shown that each miRNA can have many gene targets and that these gene targets may be different and based on cell type [44]. Moreover, the exact influence of one miRNA on gene expression may be physiologically indispensable, but difficult to identify statistically. In conclusion, this study provides new insights into the global transcriptome changes and the abundance of specific transcripts in porcine oocytes that have been correlated with follicle size.

Above all, our study has identified differently expressed miRNAs obtained from PFF EXs in differentsized follicles (groups B, C, and D) when compared to the control (group A). Using our GO and pathway analyses, we have identified different targeting cluster genes-miR-125b, let-7d-5p, miR-200b, miR-26a and miR-92a-important to porcine oocyte maturation. These miRNAs could be used as biomarkers for a better understanding of the oocyte maturation process and allow the selection of high-quality oocytes for further research. Despite this work, there remain many open questions about porcine oocyte development mechanisms related to exosomal miRNAs. For instance, how do these miRNAs control the mechanisms regarding oocyte cytoplasmic and nuclear maturation?

\section{Conclusions}

This work first showed miRNAs obtained from PFF exosomes of different-sized follicles had significantly differential expression relative to small-sized follicles. We also identified some critical miRNAs genes-miR125b, let-7d-5p, miR-200b, miR-26a, and miR-92athat may be potential biomarkers for the molecular identification of high-quality oocytes. These miRNAs may also serve as future identifiers for the mechanism behind oocyte maturation. Despite this work, research into miRNAs and porcine oocyte maturation still has many open questions that need to be answered to fully understand the molecular mechanisms behind this complicated process.

\section{Authors' contributions}

$\mathrm{JH} H$ conceived and designed the experiments, performed the experiments, analyzed the data, prepared figures and/or tables, authored or reviewed drafts of the paper, and approved the final draft. JY D and XS T conceived and designed the experiments, analyzed the data, prepared figures and/or tables, authored or reviewed drafts of the paper, and approved the final draft. Z Z and J W analyzed the data, prepared figures and/or tables, and approved the final draft. T T, J Y and CZ J performed the experiments, analyzed the data, prepared figures and/or tables, and approved the final draft. All authors have read and approved the manuscript.

\section{Funding}

This work is fully funded by the Hunan Natural Science Foundation (2019JJ40139) and Scientific research project of Hunan Education Department (20A280). The funders had no role in study design, data collection and analysis, decision to publish, or preparation of the manuscript.

\section{Availability of data and materials}

The datasets during and/or analyzed during the current study available from the corresponding author on reasonable request.

\section{Ethics approval and consent to participate}

All experiments were conducted in accordance with the Institutional Ethics Committee of Hunan University of Humanities, Science and Technology, and the sampling permission was also approved to take the samples from the animals.

\section{Consent for publication}

Not applicable.

\section{Competing interests}

The authors declare that they have no competing interests.

Received: 4 August 2020 Accepted: 7 December 2020

Published online: 14 December 2020

\section{References}

1. Mehri S, Setti PL, Greco K, Sakkas D, Martinez G, Patrizio P. Correlation between follicular diameters and flushing versus no flushing on oocyte maturity, fertilization rate and embryo quality. J Assist Reprod Genet. 2014; 31(1):73-7.

2. Anguita $B$, Jimenez-Macedo AR, Izquierdo D, Mogas T, Paramio M-T. Effect of oocyte diameter on meiotic competence, embryo development, p34 (cdc2) expression and MPF activity in prepubertal goat oocytes. Theriogenology. 2007;67(3):526-36.

3. Teissier M, Chable H, Paulhac S, Aubard Y. Comparison of follicle steroidogenesis from normal and polycystic ovaries in women undergoing IVF: relationship between steroid concentrations, follicle size, oocyte quality and fecundability. Hum Reprod. 2000;15(12):2471-7.

4. Matsuno Y, Kanke T, Maruyama N, Fujii W, Naito K, Sugiura K. Characterization of mRNA profiles of the exosome-like vesicles in porcine follicular fluid. PLoS One. 2019;14(6):e0217760.

5. Fouladi-Nashta A, Campbell K. Dissociation of oocyte nuclear and cytoplasmic maturation by the addition of insulin in cultured bovine antral follicles. Reproduction. 2006;131(3):449-60.

6. Muralidharan-Chari V, Clancy JW, Sedgwick A, D'Souza-Schorey C. Microvesicles: mediators of extracellular communication during cancer progression. J Cell Sci. 2010;123(10):1603-11.

7. Desrochers LM, Bordeleau F, Reinhart-King CA, Cerione RA, Antonyak MA. Microvesicles provide a mechanism for intercellular communication by embryonic stem cells during embryo implantation. Nat Commun. 2016;7: 11958-68.

8. Faroogi AA, Desai NN, Qureshi MZ, et al. Exosome biogenesis, bioactivities and functions as new delivery systems of natural compounds. Biotechnol Adv. 2018;36(1):328-34.

9. Di Pietro C. Exosome-mediated communication in the ovarian follicle. J Assist Reprod Genet. 2016;33(3):303-11.

10. da Silveira JC, Veeramachaneni DR, Winger QA, Carnevale EM, Bouma GJ. Cell-secreted vesicles in equine ovarian follicular fluid contain miRNAs and proteins: a possible new form of cell communication within the ovarian follicle. Biol Reprod. 2012;86(3):71 71-10. 
11. Zlotogorski-Hurvitz A, Dayan D, Chaushu G, et al. Human saliva-derived exosomes: comparing methods of isolation. J Histochem Cytochem. 2015; 63(3):181-9.

12. Sohel MMH, Hoelker M, Noferesti SS, et al. Exosomal and non-exosomal transport of extra-cellular microRNAs in follicular fluid: implications for bovine oocyte developmental competence. PLoS One. 2013;8(11):e78505.

13. Pegtel DM, Cosmopoulos K, Thorley-Lawson DA, et al. Functional delivery of viral miRNAs via exosomes. Proc Natl Acad Sci. 2010;107(14):6328-33.

14. Tesfaye D, Gebremedhn S, Salilew-Wondim D, et al. MicroRNAs: tiny molecules with a significant role in mammalian follicular and oocyte development. Reproduction. 2018;155(3):121-35.

15. Guthrie H, Grimes R, Cooper B, Hammond J. Follicular atresia in pigs: measurement and physiology. J Anim Sci. 1995;73(9):2834-44.

16. Lässer C, Eldh M, Lötvall J. Isolation and characterization of RNA-containing exosomes. J Vis Exp. 2012:59:e3037-46.

17. Sang $\mathrm{Q}$, Yao Z, Wang $\mathrm{H}$, et al. Identification of microRNAs in human follicular fluid: characterization of microRNAs that govern steroidogenesis in vitro and are associated with polycystic ovary syndrome in vivo. J Clin Endocrinol Metab. 2013:98(7):3068-79.

18. Wu Y, Deng W, Klinke DJ II. Exosomes: improved methods to characterize their morphology, RNA content, and surface protein biomarkers. Analyst. 2015;140(19):6631-42.

19. Witte $K$, Jürchott $K$, Christou $D$, et al. Increased presence and differential molecular imprinting of transit amplifying cells in psoriasis. J Mol Med. 2020; 98(1):111-22.

20. Battaglia R, Vento ME, Ragusa M, et al. MicroRNAs are stored in human MII oocyte and their expression profile changes in reproductive aging. Biol Reprod. 2016;95(6):131 131-113.

21. Foster B, Balassa T, Benen T, et al. Extracellular vesicles in blood, milk and body fluids of the female and male urogenital tract and with special regard to reproduction. Crit Rev Clin Lab Sci. 2016;53(6):379-95.

22. Hutt KJ, Albertini DF. An oocentric view of folliculogenesis and embryogenesis. Reprod BioMed Online. 2007;14(6):758-64.

23. Rodrigues TA, Tuna KM, Alli AA, et al. Follicular fluid exosomes act on the bovine oocyte to improve oocyte competence to support development and survival to heat shock. Reprod Fertil Dev. 2019;31(5):888-97.

24. de Ávila A, da Silveira J. Role of extracellular vesicles during oocyte maturation and early embryo development. Reprod Fertil Dev. 2020:32(2): 56-64.

25. Jiménez-Macedo A-R, Anguita B, Izquierdo D, Mogas T, Paramio M-T. Embryo development of prepubertal goat oocytes fertilised by intracytoplasmic sperm injection (ICSI) according to oocyte diameter. Theriogenology. 2006;66(5):1065-72

26. Yoon K-W, Shin T-Y, Park J-I, et al. Development of porcine oocytes from preovulatory follicles of different sizes after maturation in media supplemented with follicular fluids. Reprod Fertil Dev. 2000;12(4):133-9.

27. Jiajie T, Yanzhou Y, Hoi-Hung AC, Zi-Jiang C, Wai-Yee C. Conserved miR-10 family represses proliferation and induces apoptosis in ovarian granulosa cells. Sci Rep. 2017:7:41304-15.

28. Yang X, Gilman-Sachs A, Kwak-Kim J. Ovarian and endometrial immunity during the ovarian cycle. J Reprod Immunol. 2019;133:7-14

29. Li H-C, Lin Y-b, Li C, et al. Expression of miRNAs in serum exosomes versus hippocampus in methamphetamine-induced rats and intervention of rhynchophylline. Evid Based Complement Alternat Med. 2018;2018:8025206-23.

30. Guan X-I, Zhang B-c, Sun L. pol-miR-194a of Japanese flounder (Paralichthys olivaceus) suppresses type I interferon response and facilitates Edwardsiella tarda infection. Fish Shellfish Immunol. 2019;87:220-5.

31. Wu T-H, Pan C-Y, Lin M-C, Hsieh J-C, Hui C-F, Chen J-Y. In vivo screening of zebrafish microRNA responses to bacterial infection and their possible roles in regulating immune response genes after lipopolysaccharide stimulation. Fish Physiol Biochem. 2012;38(5):1299-310.

32. Ma $X$, Zhang $Y$, Qiao F, et al. Comparison of RNA extraction and microRNA detection protocols for a small amount of germinal vesicle oocytes in bovine. Anim Reprod Sci. 2018;195:112-20.

33. Li Y, Fang Y, Liu Y, Yang X. MicroRNAs in ovarian function and disorders. J Ovarian Res. 2015:8(1):51-8.

34. Donadeu F, Schauer S, Sontakke S. Involvement of miRNAs in ovarian follicular and luteal development. J Endocrinol. 2012;215(3):323.

35. German MA, Pillay M, Jeong D-H, et al. Global identification of microRNAtarget RNA pairs by parallel analysis of RNA ends. Nat Biotechnol. 2008;26(8): 941-6.
36. Fridrich A, Hazan Y, Moran Y. Too many false targets for MicroRNAs: challenges and pitfalls in prediction of miRNA targets and their gene ontology in model and non-model organisms. BioEssays. 2019;41(4): e1800169.

37. Min H, Yoon S. Got target?: computational methods for microRNA target prediction and their extension. Exp Mol Med. 2010;42(4):233-44.

38. Akhtar MM, Micolucci L, Islam MS, Olivieri F, Procopio AD. Bioinformatic tools for microRNA dissection. Nucleic Acids Res. 2015;44(1):24-44.

39. Maalouf S, Liu W, Pate JL. MicroRNA in ovarian function. Cell Tissue Res. 2016;363(1):7-18.

40. Madej A, Lang A, Brandt Y, Kindahl H, Madsen M, Einarsson S. Factors regulating ovarian function in pigs. Domest Anim Endocrinol. 2005;29(2): 347-61.

41. Madej A, Brandt Y, Einarsson S. Endocrine dynamics associated with follicle development in pigs: a review. Anim Reprod. 2018;6(1):135-43.

42. Gomez-León V, Ginther O, Guimarães J, Wiltbank M. Hormonal mechanisms regulating follicular wave dynamics $\|$ : progesterone decreases diameter at follicle selection regardless of whether circulating FSH or LH are decreased or elevated. Theriogenology. 2020;143:148-56.

43. Yang $S$, Wang $S$, Luo $A$, et al. Expression patterns and regulatory functions of microRNAs during the initiation of primordial follicle development in the neonatal mouse ovary. Biol Reprod. 2013;89(5):126 121-111.

44. Gudimella R, Singh P, Mazumdar P, Wong GR, Lau S-E, Harikrishna JA. Genome-wide regulatory network mapping of miRNA and transcription factors in banana roots. Trop Plant Biol. 2018;11(3-4):141-53.

\section{Publisher's Note}

Springer Nature remains neutral with regard to jurisdictional claims in published maps and institutional affiliations.
Ready to submit your research? Choose BMC and benefit from:

- fast, convenient online submission

- thorough peer review by experienced researchers in your field

- rapid publication on acceptance

- support for research data, including large and complex data types

- gold Open Access which fosters wider collaboration and increased citations

- maximum visibility for your research: over $100 \mathrm{M}$ website views per year

At BMC, research is always in progress.

Learn more biomedcentral.com/submissions 